\title{
AS DISCRIMINAÇÕES NO PROCESSO PENAL
}

DISCRIMINATION IN CRIMINAL TRIALS

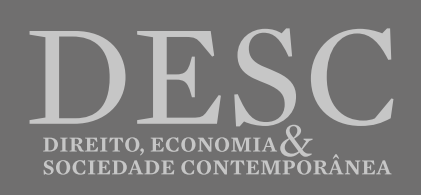




\title{
AS DISCRIMINAÇÕES NO PROCESSO PENAL ${ }^{1 *}$
}

\author{
DISCRIMINATION IN CRIMINAL TRIALS
}

PASQUALE BRONZO
Università degli Studi di Roma “La Sapienza”
pasquale.bronzo@uniroma1.it
http://www.digef.uniromal.it/ricercatore/bronzo
https://orcid.org/0000-0002-9374-2235

Resumo: o texto aborda a discriminação de algumas pessoas, notadamente os imigrantes, no que respeita à administração do sistema penal e processual penal. Tal modo de pensar altera a forma pela qual tais pessoas são tratadas pelo Estado, que parte do pressuposto se que são predispostas a delinquir, levando mais à punição pela pessoa do que pela gravidade do fato, perpassando pelos próprios institutos processuais que se aplicam ao caso, tais como a prisão cautelar, um procedimento despido de formalidades e a menor aplicação de sanções alternativas.

Palavras-chave: discriminação, imigrantes, sistemas penal e processual penal

\begin{abstract}
: the text addresses the discrimination of some people, especially immigrants, with regard to the administration of the criminal and criminal procedure system. Such a way of thinking changes the way in which such persons are treated by the State, which is based on the assumption that they are predisposed to commit a crime, leading to more punishment by the person than by the gravity of the fact, passing through the procedural institutes themselves which apply to the case, such as the precautionary prison, a procedure without formalities and the lower application of alternative sanctions.
\end{abstract}

Keywords: discrimination, immigrants, criminal and criminal procedural systems

\section{Nota introdutória à versão brasileira}

Em sociedades e épocas em que há fortes problemas de pobreza (devido a recessões econômicas, por exemplo) ou fortes problemas de marginalidade social (devido a migrações em massa, por exemplo), um grave perigo é que o direito penal e a justiça penal em vez de reduzir as desigualdades entre as pessoas, como seria natural, elas determinam seu

1 *Intervenção na Conferência 'Igualdade e discriminações' («Uguaglianza e discriminazioni»), Sapienza Università di Roma, já publicado em Critica del diritto, Esi, 2017, f. 1., p. 186 ss. Traduzido por Bruno Cunha Souza, mestrando em Direito, com ênfase em Direito Econômico e Desenvolvimento, pela Pontifícia Universidade Católica do Paraná, bolsista na modalidade Taxa da CAPES/PROEX. 
agravamento. A análise que se segue diz respeito à Itália, mas é válida até mesmo para a realidade brasileira. Apesar de não haver ainda estudos sistemáticos indicando distorções do tratamento processual e penal do imigrante legal ou ilegal no Brasil, a criminalidade ordinária que aflige os povos, especialmente sul-americanos que vivem no Brasil para fugir de crises, pobreza ou violência, é já identificada como um problema à parte. A reflexão sobre os riscos de discriminação e perseguição a estrangeiros revelados pelos teóricos do processo na Itália, assim como em outros países da Europa, oferece um intercâmbio necessário para que os juristas nacionais tenham referências ao lidar com a imigração, especialmente em massa, a exemplo do recente caso das imigrações de venezuelanos na região norte do país, sem perder de vista também as diferentes realidades regionais no Brasil.

\section{1. «Classes perigosas».}

Quero falar-vos sobre discriminações e de processo penal. Parece-me que a questão mais séria de discriminação diz respeito, hoje, às pessoas imigrantes. Não me refiro às normas penais processuais ou substanciais em si, a como estão escritas e estruturadas, mas a como elas 'vivem', naquilo que Luigi Ferrajoli chama de "subsistema penal de polícia"2(NT) - tipo penal (fattispecie) que vincula efeitos jurídicos não a um fato ou a um comportamento, mas a um status subjetivo; normas que não proíbem de agir de certa maneira, mas que proíbem de ser de determinado modo ${ }^{3}$.

Neste subsistema, uma série de pré-conceitos (schemi presuntivi) sobre os imigrantes 'geradores de insegurança', em razão da associação que comumente se faz entre imigração e criminalidade - condicionam os mecanismos processuais e, em geral, as decisões penais. Generalizações como essas, segundo as quais 'os imigrantes tendem a delinquir', contribuem para construir uma realidade, que alimenta uma atividade processual baseada em préconceitos dificilmente superáveis. Até mesmo os defensores, em última análise, participam dessa consciência dada por descontada e, com base nela, orientam as próprias estratégias defensivas: quando o advogado deve decidir quantos recursos empregar na defesa do assistido, aqueles pré-conceitos pesam; quanto mais ele está convencido que o crime imputado apresenta caráter de 'normalidade' em relação à pessoa a ser julgada, maior a probabilidade de que a sua defesa se reduza a uma presença formal, e que se sirva de fórmulas defensivas de estilo sem ativar nenhum recurso processual particular.

Essa incidência de pré-conceitos coloca em crise não apenas o princípio da legalidade,

2 (NT) A expressão escolhida também foi adotada na tradução de Fauzi Hassan Chouckr em: L. Ferraioli, Direito e razão: teoria do garantismo penal. 4. ed. São Paulo: Editora Revista dos Tribunais, 2014. p. 704 ss.

3 L. Ferrajoli, Diritto e ragione. Teoria del garantismo penale, Roma-Bari, Laterza, 1990, p. 795 ss. 
mas também o princípio da jurisdicionariedade estrita, tão precioso em matéria penal, em detrimento da atenção que um sistema de justiça 'cognitivo' deveria dar à verificação dos fatos que constituem crime segundo a lei penal.

Há algum tempo, um amigo me aconselhou a ler um trabalho de Giuseppe Campesi, um sociólogo que analisou - empiricamente, estudando dados estatísticos e entrevistando os operadores - um particular segmento do nosso sistema judicial penal que exemplifica muito bem esse "subsistema penal", formulando observações interessantes sobre os processos de construção simbólica da criminalidade que hoje gostaria de transmitir-vos. O estudo analisava as dinâmicas dos processos por diretíssima - em todas as fases em que isso se compõe: prisão, convalidação da prisão, aplicação de uma medida cautelar, escolha dos ritos alternativos, julgamento, imposição de pena, execução de condenação - descrevendo como ser uma pessoa em certa medida "perigosa", ou, melhor, pertencer a «classes perigosas», acaba por tornar-se o pressuposto de uma punição, uma espécie de «infrapenalidade» ${ }^{4}$.

\section{As "diretíssimas".}

Ao processo "por diretíssima" normalmente se chega após uma prisão em flagrante, e por escolha do ministério público. A lei lhe permite fazer na sequência da prisão um juízo diretíssimo mesmo que o iter ordinário quando entende que não ocorrerão investigações particulares, e então segundo uma avaliação amplamente discricionária. Na realidade, a escolha entre o rito ordinário e o diretíssimo - aquela discricionariedade - responde principalmente a critérios que não têm que lidar com a complexidade instrutória, mas com a exigência de dar uma resposta imediata à criminalidade que suscita um grande clamor social.

Em muitas procurações, é 'conveniente' adotar a via diretíssima em caso de prisões por crimes de competência de juiz monocrático, que representam a criminalidade de rua, uma típica expressão de desigualdade social (disagio sociale). A escolha do rito é, portanto, uma escolha de política criminal: à repressão desses delitos reserva-se uma via preferencial, porque por meio dessa aceleração do iter processual esses crimes - que seriam do contrário destinados à prescrição, em razão das penas não serem particularmente elevadas - são punidos antes que possam prescrever.

$\mathrm{Na}$ prática, os mais recorrentes são, ao lado dos crimes leves contra o patrimônio, os casos de "pequeno tráfico" ( $c$ d. piccolo spaccio): uma pessoa é pega no ato de ceder uma pequena quantidade de droga ou mais frequentemente no ato de possuir a droga; a posse para uso pessoal não é crime, mas uma violação administrativa (e, portanto, não permite arresto

4 G. Campesi, Il controllo delle «nuove classi pericolose»: sottosistema penale di polizia e immigrati, in Dei delitti e delle pene, 2003, p. 145 ss. A noção de "classes perigosas" mudou de Luigi Ferrajoli (Diritto e ragione, cit., p. 214), que utiliza o léxico do Texto único da lei de segurança pública (italiano) de 30 de junho 1889, n. 6144, predecessora do vigente de 1931. 
algum); e assim, uma conduta penalmente neutra se torna - em virtude de pré-conceitos penalmente punível.

Sem esquecer as diferenças de pena entre o pequeno tráfico e o tráfico, entre o tráfico ocasional e o habitual, que dependem não só de um dado quantitativo objetivo, mas também da modalidade ou circunstâncias da ação: o que diferencia o coração das investigações do fato ao autor, ao seu modo de viver e de ser. Obviamente para as autoridades judiciárias e policiais é dificílimo fazer esse tipo de avaliação - naqueles contextos de urgência, sobretudo - se não aplicando precisamente pré-conceitos, ou seja, interpretando circunstâncias, que por si são penalmente irrelevantes, à luz de noções de senso comum.

Quanto mais a pessoa se assemelhar ao traficante típico, maior é a possibilidade de uma detenção por tráfico parecer verossímil: a hipótese do traficante habitual se tornará preferível à do traficante ocasional. Eis que, então, a punição ou a severidade da punição, que deveria ser modulada com base na gravidade do fato, acaba sendo calibrada por dados pessoais.

Então, como é construído o tipo de traficante estrangeiro não europeu (extra-comunitario)? A falta de trabalho, ou a impossibilidade de encontrar um devido à clandestinidade, faz com que essas pessoas - nesse sentimento comum que influencia os atores processuais fatalmente decide ao delito; é por outro lado a mesma presença irregular sobre o território italiano a representar o sintoma de uma escolha de vida criminal, a vontade de eludir todo tipo de controle social; teoriza-se nas mãos de clandestinos a indústria do tráfico de droga, em que os operários - geralmente imigrantes norte-africanos - constituem um novo proletariado criminal, que acaba na máquina repressiva da diretíssima.

Dentro dessa construção poderosa, o fato de, por exemplo, essas pessoas serem encontradas com pouquíssima quantidade de substância estupefaciente não qualifica necessariamente um uso pessoal, mas pode até indicar uma capacidade criminal mais elevada: delinquentes "muito inteligentes", que souberam esconder em outro lugar outras quantidades de drogas.

Em síntese, hoje o imigrante não europeu tomou o lugar que no direito policial oitocentista ocupavam os "ociosos e vagabundos". A ideia de base é que a condição de marginalidade não deixa escolha alguma senão aquela de viver de crimes, e que a intervenção penal serve para possibilitar um processo de "disciplinamento" capaz de, se não normalizar a vida dessas pessoas, pelo menos reduzir a periculosidade delas, tornando a escolha pelo crime menos atraente e mais arriscada.

\section{A prisão em flagrante.}

A imagem desse universo delinquente de imigrantes e pequenos traficantes influencia até mesmo antes das escolhas dos atores processuais, decisões anteriores ao processo: as decisões 
sobre a prisão, sobretudo, que são tomadas pelas forças policiais.

As prisões em flagrante são uma parte das atividades de controle do território, guiadas pelas autoridades policiais de comando, que muitas vezes têm serviços "direcionados", destinados ao combate de certos crimes, que causam particular alarme social.

A prisão em flagrante, então, dá partida - como dito - na máquina da diretíssima, que permite alcançar a condenação por crimes que, quando tratados segundo as regras do procedimento penal ordinário, dificilmente seriam julgados (accertebili) antes de serem engolidos pela prescrição.

Podemos dizer, portanto, que o poder de prisão representa, de fato, um poder de política criminal cujo exercício depende da seleção dos crimes que serão julgados e os que nunca serão, e que, portanto, a seleção das pessoas a serem processadas criminalmente (a criminalização secundária) é gerida, nessa medida, pela autoridade policial. Em suma, há um "saber" socialmente difuso sobre o crime - que, então, condiciona o "saber" processual.

Por outro lado, para o crime de rua a prisão é «facultativa»: o agente da força pública, diante de um crime em flagrante, deve-se prender somente se avalia-se o fato como grave e o sujeito como 'perigoso'. Mas se a gravidade de um fato é já mais intuitiva, o que dizer da periculosidade, deduzida, além das circunstâncias do fato, da "personalidade" do sujeito?

Assim, prendem-se pessoas que correspondem a tipos de sujeitos perigosos, e, particularmente, aquelas que, por suas condições socialmente desfavorecidas, deixam fundadas as suspeitas de que vivem de crimes. Não qualquer traficante ou batedor de carteiras, mas somente o traficante "normal" e o batedor de carteira "normal". Se Antônio é pego com uma pequena quantidade de haxixe é fácil que não seja sequer denunciado, que seja a posse considerada para uso pessoal, e a violação administrativa ainda é contestável. Não é assim se com a mesma quantidade e tipo de substância param Mohammed.

De resto, para o crime 'de rua', a prisão faz mais sentido quanto mais previsível for a aplicação (ou pelo menos a aplicabilidade) de uma medida cautelar; para esse tipo de crime, as medidas cautelares são aplicadas quando há um risco de reiteração; e esse perigo - «concreto e iminente», como exige o art. 274 do CPP italiano - é fatalmente mais fácil de ser considerado verossímil para Mohammed do que para Antônio.

Obviamente, em sede de convalidação, o juiz bem poderia aprofundar a valoração acerca da periculosidade social do detido, mas a rotina tende a fazer próprias as valorações da polícia e do ministério público. Valorações que frequentemente são baseadas, mais que sobre $\mathrm{o}$ ato flagrante e, podemos dizer, mais que sobre a pessoa presa, sobre a «classe» de pessoas perigosas a que ela pertence.

As estatísticas judiciárias dizem que as convalidações das prisões se aproximam de 100\%, 
e que, de qualquer forma, as convalidações faltantes fundamentam-se sobre uma valoração diversa da do judicante em razão do pressuposto da periculosidade subjetiva do arrestado. Por outro lado, é de praxe que as forças policiais, antes de proceder à prisão, contatem por telefone o ministério público (que será, então, aquele que preparará a documentação para a convalidação e posterior julgamento) para avaliar se para aquela pessoa tem sentido ou não pedir a aplicação de uma medida cautelar.

A polícia judiciária, por sua vez, teme muito a falta de convalidações, que criam problemas de produtividade e de relações internas. Os modelos operativos dos órgãos de polícia se fundam em certa medida sobre um "saber" compartilhado tanto pelos membros do ministério público, como pelos julgadores.

Nos casos de que estamos falando, em resumo, a pessoa presa muito provavelmente terá sua prisão convalidada: afinal, o juízo de convalidação se funda na oitiva do preso e do agente, o que significa que as palavras deste último são praticamente irrefutáveis, enquanto sobre aquelas do preso pesa a carga do julgamento social negativo.

\section{As medidas cautelares.}

Convalidada a prisão, seguirá, da mesma forma, a aplicação de uma medida cautelar. Não obstante não haja mais os delitos de prisão (cattura) obrigatória do código de 1930 , nestes casos a verificação dos pressupostos cautelares é ainda muito condicionada por préconceitos, que atingem os saberes práticos, por sua vez influenciados por convicções de senso comum. Quanto ao fumus delicti, a prisão em flagrante resolve a questão; para o periculum libertatis, entre aqueles que podem justificar uma medida, há um - que então é o que mais frequentemente encontramos nas motivações dos provimentos cautelares - fortemente exposto ao uso dos pré-conceitos dos quais estamos falando, ou seja, o perigo de reiteração criminosa ou de cometimento de crimes mais graves. O prognóstico de reiteração se exaure de fato, na maioria dos casos, na constatação das mesmas circunstâncias que justificam a inclusão do preso na classe perigosa: a irregular presença no Estado, a identidade incerta, a falta de fonte de renda lícita.

Acustódia cautelar aqui não tutela o processo, é antes um modo de neutralizar temporariamente pessoas perigosas: pelo contrário - como o prognóstico de reiteração não é quase nunca fundado sobre condições individuais específicas, mas sobre considerações genéricas concernentes à categoria de pertencimento - Campesi sugere que ela é um modo de neutralizar classes de pessoas perigosas. E é singular - observa, então - que, no processo, a perícia criminológica (para estabelecer o caráter e as atitudes delinquentes) seja vedada até mesmo aos especialistas, enquanto na fase cautelar é admitido o recurso a "saberes difusos" sobre o crime. 
Nós sabemos que os estereótipos deveriam, no máximo, servir como "base" para interpretar dados objetivos: por exemplo, os antecedentes (precedenti) penais, uma atividade laboral, um domicílio. O problema, porém, é que esse tipo de dado muitas vezes não está presente. Geralmente são pessoas sem identidade, com dez apelidos, e, portanto, sem antecedentes. Ainda mais frequente são as pessoas sem trabalho visível, porque "clandestino" ("nero"). Sofrem, portanto, duas vezes por suas condições: com a baixa retribuição e as más condições jurídicas e materiais que o trabalho clandestino comporta, e com a aplicação de pré-conceitos de periculosidade que o trabalho clandestino, sinônimo de marginalidade socioeconômica, justifica. Paradoxalmente, ter um pouco de dinheiro no bolso torna-se motivo de suspeita, porque - assim como acontecia ao final do século XIX com os ociosos e os vagabundos - eles são onerados da prova diabólica de que aquele dinheiro não é fruto de ganhos ilegítimos.

Muitas vezes, trata-se de pessoas sem domicílio, ou sem domicílio seguro. E isso afeta não só o prognóstico cautelar, mas também a dosagem da restrição, ou seja, a escolha do tipo de medida a aplicar no rol à disposição do julgador: a prisão cautelaré, de fato, considerada a única alternativa, visto que as prisões domiciliares são impraticáveis ou inadequadas para satisfazer a necessidade de precaução. Eis porque os estrangeiros não europeus (extracomunitari) presos em via cautelar por crimes punidos com sanções não particularmente altas acabam cumprindo em prisão cautelar toda a pena (em geral a custódia preventiva sub-roga uma pena que poderia não chegar jamais): a restrição cautelar se transforma, na verdade, não diversamente da prisão em flagrante, em uma medida de controle de pessoas perigosas.

\section{O processo.}

Nesse ponto, de fato, o "processo" é de pouca utilidade. Para os sujeitos tratados com a máquina das diretíssimas, a fase do julgamento, aquela que conduz ao acertamento da responsabilidade, termina por desenvolver-se de forma muito contraída, porque na maioria das vezes o imputado decide optar por um rito especial (abbreviato ou patteggiamento): o juiz que convalidou a prisão já expressou uma clara valoração em termos de responsabilidade e culpa, de modo que a defesa das acusações sobre o mérito é muito dificultada.

Em abstrato, o patteggiamento seria preferível ao juízo abreviado (giudizio abbreviato), porque, mesmo que a sentença venha rapidamente, a pena pode ser prevista em sua substância e se projeta mais contida. No juízo abreviado, entretanto, os juízes tendem a partir de limites em média mais altos em relação àqueles que se consideram como resultado de um juízo ordinário ('reagem' desse modo à proibição que a lei lhes impõe de incongruência da pena em relação ao fato, erodindo o efeito premial reconhecido ao acusado). E, sobretudo, o patteggiamento pode ser subordinado à suspensão condicional da pena. Nos casos que estamos considerando, 
porém, a suspensão não vem quase nunca concedida, mesmo pela oposição de membros do ministério público, que -na crença que uma pena curta constitui um oportuno 'gosto de prisão' - condiciona o aceite do patteggiamento à própria ausência de pedido de suspensão condicional.

$\mathrm{E}$ assim resulta mais frequente o pedido de rito abreviado, e a aceitação do risco de uma pena muito mais severa em relação ao acordo que se fosse possível pactuar com o acusador, com a única consolação de que isso, pelo menos, não virá muito cedo.

A opção do imputado pelo julgamento abreviado, como é notório, implica, porém, a aceitação de um método de acertamento "inquisitório", substancialmente fundado sobre atos de procedimento de convalidação, e comprime muito o direito a contraprovar as acusações de maneira eficaz.

\section{A pena.}

Também na graduação da sanção vem aplicada ao êxito do julgamento, os pré-conceitos não são menos perigosos. O nosso (italiano) código penal contém uma norma muito genérica, o art. 133 c.p., que remete substancialmente ao juiz a dosimetria concreta da pena, com possibilidade de avaliar tudo, mesmo a condição pessoal de marginalidade social.

E se a desigualdade social por anos tem jogado a favor do condenado, conduzindo a valorações vagamente indulgentes na mensuração da pena, nas últimas décadas a situação se inverteu: a imagem criminalizante do imigrado traficante representa, naquele cálculo, um fator de agravamento. Isso é confirmado pelos dados sobre a concessão da suspensão condicional da pena: uma volta se alargava, quase como se fosse tratar de um automatismo, em caso de incensurados; hoje, não obstante a eventual incensurabilidade, o seu pertenciemento a classes perigosas, a bandos de marginalidade social, sugere negá-la. A ausência de documentos, por exemplo, sugere um projeto migratório criminal expresso.

Também na dosimetria da pena, em suma, pesam os estereótipos.

\section{Notas conclusivas.}

Essas descobertas são importantes se se deseja individualizar exatamente os motivos pelos quais nossa população carcerária é constituída em uma medida relevantíssima de imigrantes (um a cada três presos) $)^{5}$. Por outro lado - diz-se incidentemente - para essa categoria de presos a expiação é normalmente toda em prisões, já que medidas alternativas de detenção e trabalho externo encontram, nas condições de marginalidade social dessas pessoas, fortes limites de

5 Trata-se de um percentual elevado mesmo a nível europeu, considerando obviamente percentuais de imigrações em qualquer país. (V. Militello - A. Spena, Il traffico di migranti: Diritti, tutele, criminalizzazione, Torino, Giappichelli, 2015, p. 297). 
aplicabilidade: uma expiação, portanto, pobre de ofertas de tratamento e de reduzida eficácia reeducativa, que arrisca esgotar toda real utilidade na dimensão da custódia.

Agora, se as generalizações, além de serem em uma certa medida inevitáveis, não são um mal em si - são, de fato, onde empiricamente se fundam (id quod plerumque accidit), um recurso precioso na administração da justiça porque economicamente vantajosas $^{6}$ - na máquina da diretíssima elas favorecem a instrumentalização dos institutos processuais com papel de controle social, distanciando o processo da sua função cognitiva.

Por um lado, o fornecimento probatório - além dos resultados da atividade policial - se exaure na audição da pessoa presa e do agente. Por outro, as avaliações sobre a convalidação, e aquelas necessárias para decidir o pedido cautelar, mudam o foco da investigação processual das circunstâncias do fato às condições e qualidade do imputado.

Os tempos já limitados do julgamento são geralmente gastos principalmente na avaliação de antecedentes, situações de vida, condições familiares, atividade de trabalho: perfis (normalmente irrelevantes, em um processo penal ordinário) para estimar quais dados biográficos espalhados nos atos usa o juiz, interpretando-os à luz dos seus "saberes práticos".

O tema central do julgamento se torna se a pessoa presa corresponde ao tipo de autor do crime imputado, ao tipo-traficante ou ao tipo-batedor de carteira; e os estereótipos, fatalmente, preenchem as lacunas do quadro instrutório à disposição do juiz.

Deve-se também a essas dinâmicas se as instituições penitenciárias assumem funções, e aparência, dos 'hospitais gerais' que no século XVII eram abrigos para sociopatas, marginais, mendigos, desajustados, marginais, limítrofes.

Antídotos? Não vejo muito mais que um legislador cuidadoso, na construção dos tipos penais, para garantir a taxa necessária de objetividade e uma jurisdição 'forte’ na sua função de garantia contra os excessos do subsistema policialesco-disciplinar.

6 F. Shauer, Di ogni erba un fascio. Generalizzazioni, profili, stereotipi nel mondo della giustizia, Bologna, Il Mulino, $2008,31$. 


\section{Referências}

CAMPESI, G. Il controllo delle «nuove classi pericolose»: sottosistema penale di polizia e immigrati, in Dei delitti e delle pene, 2003.

FERRAJOLI, L. Diritto e ragione. Teoria del garantismo penale, Roma-Bari, Laterza, 1990. MILITELLO, V.; SPENA, A. Il traffico di migranti: Diritti, tutele, criminalizzazione, Torino, Giappichelli, 2015.

SHAUER, F. Di ogni erba un fascio. Generalizzazioni, profili, stereotipi nel mondo della giustizia, Bologna, Il Mulino, 2008.

\section{SOBRE O AUTOR:}

\section{Pasquale Bronzo}

Pesquisador de Direito Processual Penal, professor de direito penitenciário, Faculdade de Direito da Università degli Studi di Roma "La Sapienza"

$$
\begin{aligned}
& \text { DESC } \\
& \text { SOCIEDADE CONTEMPORÂNEA }
\end{aligned}
$$

